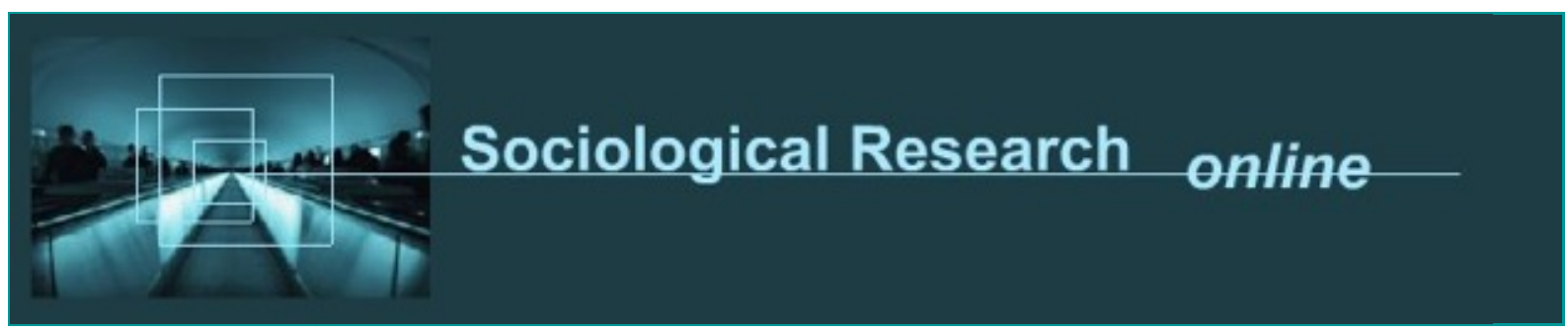

\title{
The ESRC's 2010 Framework for Research Ethics: Fit for Research Purpose?
}

\author{
by Liz Stanley and Sue Wise \\ University of Edinburgh; Lancaster University
}

Sociological Research Online, 15 (4) 12

<http://www. socresonline.org.uk/15/4/12.htm/>

$10.5153 /$ sro.2265

Received:27 Sep 2010 Accepted: 20 Nov 2010 Published: 30 Nov 2010

\begin{abstract}
The ESRC's (2010) Framework for Research Ethics extends the remit of its 2005 research ethics framework in three significant ways: the system is to be fully mandatory and it will no longer be possible to make the case that no out of the ordinary ethical issues arise; the Research Ethics Committees (RECs) set up under the ESRC's 2005 document have extended remit, including reviewing all research proposals accepted by the ESRC and other funding bodies; and funding will depend on the REC review, with its purview extending through a project's life. The 2010 document is reviewed in detail and the conclusion is drawn that it is not fit for purpose. Six wider issues raised by the FRE document are discussed: the consultation process by the ESRC was insufficient and the informed consent of the social science community was not obtained; the ethics creep involved will involve unnecessary bureaucratisation; the RECs will operate without expert discipline-specific knowledge using unethical generalist criteria; the overall effects long-term will be deleterious to the research base; the FRE document unacceptably ignores the professional associations and their research ethics guidelines; and the ESRC's system of the expert peer review of funding applications will be undermined.
\end{abstract}

\section{Keywords: Framework for Research Ethics, ESRC, Research Ethics, Audit Creep}

\section{Introduction}

1.1 In March 2010, the Economic and Social Research Council (ESRC), the UK's principal body for funding social science research, published its Framework for Research Ethics. The Framework for Research Ethics (FRE) combines aspects of the ESRC's 2005 Research Ethics Framework with new provisions, including mechanisms to ensure compliance. In three major respects, the FRE establishes a significantly extended system of governance for research ethics which will become mandatory for UK social scientists seeking ESRC funding. These extensions are, firstly, the system is to be fully mandatory, in the sense that it is no longer possible, as previously, for research applications to make the case that no out of the ordinary ethical issues arise; secondly, the Research Ethics Committees (RECs) set up in the ESRC's 2005 document have been reconfigured, with their extended remit including reviewing all research proposals accepted by the ESRC and other funding bodies; and thirdly, funding will depend on the REC review, with its purview extending through a project's life.

1.2 The 2010 document represents an important shift and in effect establishes a dual system for research funding, involving on the one hand the ESRC and its assessors of research applications, and on the other institution-located Research Ethics Committees with purse-string powers. The FRE document has profound but we think largely unappreciated consequences for how research receiving ESRC funding from now on will need to be designed, carried out and monitored, as well as important implications for how the ESRC's expert peer assessor system will operate over the longer term. A major review of informed consent and the research process emphasises that the social science community is very clear that 'anything goes' is not viable with regard to research ethics, but at the same time it also highlights dissatisfaction within the social science community with current REC practices that are less onerous than those proposed (Wiles et al 2007, Crow et al 2006), so it appears that the ESRC has failed to take cognisance of research which it itself funded, which cogently argues the need for guidance rather than a model of regulation drawn from the NHS. For researchers who have to deal with the NHS RECs are only too aware of the lack of disciplinary expertise that is evident in their workings, where qualitative knowledge is often in the hands of nurse researchers who have to manage the power relations within RECs between themselves and doctors/consultants who can dismiss or challenge its design and methodology without understanding them.

1.3 In addition, the 2010 FRE sidelines or indeed disparages the role of professional organisations and guidelines regarding research ethics in the social sciences. The professional bodies of sociologists, anthropologists, political scientists and social policy specialists have no place within the FRE framework, while for us an ethics framework that does not proceed from the ethical guidelines of the relevant professional associations is deficient and lacks intellectual credibility. This ignoring of disciplinary guidance 
is also a failure to recognise how light-touch' approaches could be better implemented by some deference/recognition of difference amongst research communities and also provide RECs with the opportunity to appropriately refer to and make use of disciplinary guidelines.

1.4 In what follows, some of the more worrying aspects of the FRE document are focused on. However, this does not indicate agreement with content not specifically criticised. The structural features commented on are of such import as to remove the possibility of treating the document as a curate's egg, only bad in parts; the Framework for Research Ethics must be responded to as bad in its entirety and lobbied against by the social science community.

1.5 We realise that much of what is in the 2010 Framework for Research Ethics document is contained in its 2005 predecessor. However, the three extensions of the ethics review system referred to in 1.1 result in something new in kind, rather than different in degree, as the discussion following will show. The 2005 framework established a broad system with policy and detail dealt with locally and funding decisions remaining entirely in the hands of the ESRC; the 2010 framework establishes, alongside the ESRC assessor peer review system, a structure of trained funded RECs which can call independent scholarly experts to support the ethics reviewing on which funding will depend.

1.6 We agree with Hammersley's (2009) assessment of the ESRC's less far-reaching 2005 Research Ethics Framework predecessor, including that it is the ESRC's entire approach to ethics review in the social sciences which is the root problem and what is required is a collective rather than individualist response to this from the research community. There is a creeping ethicism at work here, with the 2005 framework already intrusive and more suitable for researchers of body tissues and drugs trials than interviewing in Plymouth, ethnography in Stirling and reading documents in Belfast, with the 2010 framework drawing much mundane research into purportedly 'higher risk' categories. [1] 'Ethics creep' combines Hammersley's (2009) strictures about an ethicsism removed from the complexities of research practice, and Lederman's (2006b) 'mission creep' in relation to ethics and Institutional Review Boards in the US. ${ }^{2]}$ The likely next step in the UK, as has happened in the US and elsewhere, is to eventually extend the system to unfunded research too (Lederman 2006b, Bradburd 2006), with extremely worrying consequences for disciplinary research bases.

\title{
'Minimum requirements' and FRE governance procedures
}

2.1 Section 1 in the Framework for Research Ethics, which details 'Minimum Requirements', composes the main substance of the document. Section 2 consists of 'Frequently Asked Questions', 'Assessing Risk', 'Consent', 'Vulnerable Groups', and 'Research Governance and Ethics'.

2.2 The beginning statement is that 'The ESRC does not seek to impose a detailed model for ethics evaluation and conduct on researchers or research organisations' (ESRC 2010: p7). ${ }^{[3]}$ However, this is belied by the document's contents, which constitute a mandatory system spelled out in some detail, including regarding the role of the Research Ethics Committees (RECs). Now 'normally' all research proposals 'involving human participants and personal data, and sensitive personal data, in particular those groups noted in Para 1.2.3 below, will require a full review and approval by a REC' (2010: 1.1.2, p7). The first of the major changes which the Framework for Research Ethics (FRE) heralds then follows, that:

\begin{abstract}
'Grant applications to the ESRC must provide a full statement by the proposers that proper consideration has been given to any ethics issues which the proposal raises. Where an ethics review is yet to be undertaken, this should be stated. All ESRC-funded awards must be approved by at least a light touch ethics review. In the previous framework some proposals could state that an ethics review was not necessary. In the light of difficulties that have arisen it is now required that all ESRC proposals are approved by at least light touch review.' (2010: 1.1.3, p7)
\end{abstract}

'If review by the REC shows that a project requires major changes which will alter it so much that it can no longer attract ESRC support, no payment will be made.' (2010: 1.1.5, p.7)

2.3 All research proposals seeking ESRC funding must now comply with the mandatory FRE system of review; and, within this, all 'successfully funded' proposals will have their funding contingent on passing the review carried out by institutionally-based Research Ethics Committees, which have powers to require changes on which funding will depend and also to recommend the withdrawal of funding completely. Although there is the further comment that this is likely to be 'an extremely rare occurrence' (2010: 1.1.5, p7), it becomes clear it is not possible for the ESRC to guarantee this, given the independence of evaluation and judgement it has accorded the RECs, as discussed later. The institution of what is in effect a dual system constitutes a major change in the way UK social science research funding is awarded and, as discussed later, also monitored thereafter as well; and it has equally consequential implications for research design and conduct too, not least because the so-called 'light touch ethics review' component of the document turns out to have a very heavy hand. The implications for the present scholarly review of ESRC funding applications by academic expert assessors are now discussed, before returning to the REC review process.

\section{The ESRC, its expert peer assessors and the FRE framework}

3.1 It is not easy to work out precisely what the FRE document implies for the ESRC's present assessor system, of the scholarly peer review of the academic merits and standing of research proposals submitted under its various funding schemes. However, tucked away under the heading of 'Responsibility for securing ethics review' (2010: 1.3.2, pp10-11), a concluding paragraph comments that,

'During peer review, referees and other assessors will be asked to comment on the ethics assessment in the proposal. If they disagree with the proposed approach to ethics issues, this could lead to the rejection of a proposal, or the making of a conditional award based upon their assessment of the necessary ethics review.' (2010: 1.3.2.8, p11) 
assessment now made mandatory at application stage. However, although decision-making by the ESRC on research funding applications will still use assessor reports, final funding approval decisions will be made by the RECs (2010: 1.1.5, p7). Also it is not possible to appeal back to the ESRC about REC decisions and requirements, with appeals being either internal to the institution in which an REC is based, or else to another REC with reciprocal arrangements for hearing each other's appeals (2010: 1.12.3, p18). The latter is rightly taboo regarding the external examining system because of its 'good old boys together' possibilities and we are astonished at its enshrinement in the FRE document.

\subsection{In addition, the 'ESRC rules' (2010: pp4-5) in the FRE summary includes:}

'During peer review, referees and assessors will be asked to comment specifically on whether they agree with the ethics assessment in the proposal.' (2010: p4)

'If referees or assessors disagree with the proposed approach to ethics within the application, this will either be grounds for rejection of an application where it calls into question researcher competence or the feasibility or validity of their proposal, or for a conditional award requiring further review or feedback to be taken into account.' (2010: p4)

This too suggests that the ethical dimension of research proposals will be evaluated by the ESRC's assessors, who will be expected to specifically comment on a proposal's ethics assessment and can recommend rejection of a proposal or for an award to be conditional on further review after feedback and changes.

3.3 So far so good for those who think that requiring an ethical assessment component to all social science research proposals is a 'good thing' in principle. But not so good for those who approve of - and for us as for a good many colleagues also help make work - the ESRC's system of scholarly peer review of research funding applications. That is, it is difficult to see the point of assessors evaluating the ethical assessments in such applications when this is the raison d'être of RECs which can compel changes and monitor research post-review. It is difficult not to conclude that the ESRC is de facto diminishing the importance of scholarly peer review of funding applications, when the RECs will be able to develop their own working practises and rules of thumb about risk, consent, sensitivity and so on, but without having the discipline-specific expertise to understand what these mean in the context of specific methodologies and paradigms and particular research situations. Stated baldly, the logic of what the FRE document contains is that ESRC will in effect become no longer the final decision-maker about its own funding, with such decisions made on general ethicist grounds determined by RECs, rather than on scholarly disciplinary criteria decided through the peer review system by expert assessors.

3.4 It may be thought we are being unduly alarmist about the Research Ethics Committee component of the new ethical framework and what this heralds - although we doubt this will be so for those who have read the FRE document with careful attention. Our assessment is connected with how the RECs are perceived and positioned in the 2010 framework, and how their competencies and powers are delineated. We now consider this in some detail.

\section{The FRE system, research funding and the local RECs}

4.1 As noted earlier, an ethics review and clearance is now mandatory for all applications for funding by the ESRC, with funding dependent on the review by an REC (2010: 1.1.3, p7). This is a change from the 2005 framework: a researcher can no longer make the case there are no particular or significant ethical problems regarding a particular piece of research, but must go through the review process; and the researcher's assessment of degrees of risk and the appropriateness of standard scholarly ways of handling the ethical aspects of research becomes something the RECs adjudicate, although this will already have been evaluated by assessors for the ESRC.

4.2 The FRE document makes it quite clear funding will be dependent on REC approval:

'Initial payment of grant will only be made once any necessary REC approval is secured. Approval for minor changes to a project following REC review is delegated to the $R O$, though the ESRC needs to be informed of any changes made and of the final decision to approve or not.' (2010: 1.1.4, p.7)

'If review by the REC shows that a project requires major changes which will alter it so much that it can no longer attract ESRC support, no payment will be made. This is likely to be an extremely rare occurrence since the proposal will have already been subject to external peer review which should identify such severe problems.' (2010: 1.1.5, p7)

While the latter is identified as 'likely to be extremely rare', the former possibility of changes is by implication not going to be.

4.3 Something of what might be entailed in applying for ethics clearance to an REC is indicated by the substantial list of things that submissions to an REC would likely include:

- 'Aims of the research and scientific background of the research

- Study design

- Participants - who (inclusion and exclusion criteria), how many, how potential participants are identified and recruited

- Potentially vulnerable groups

- Methods of data collection

- Methods of data analysis

- Response to any conditions of use set by secondary data providers

- Principal investigator's summary of potential ethics issues and how they will be addressed

- Benefits to research participants or third parties

- Risks to participants or third parties, physical, emotional and situational, and what has been done to assess, obviate or minimise risks 
- Risks to researchers, physical, emotional and situational, and in particular how researchers will be protected/supported especially in the field and outside the UK

- Procedures for freely given and adequately informed consent - information provided and methods of documenting

- Procedures for dealing with information arising in the course of fieldwork that is a cause for concern, such as disclosures from participants or behaviours or incidents observed that raise significant concerns about the safety or well-being of participants or other people

- How any data collected will be kept secure and methods of transferring data within teams

- Any data sharing outside the proposed research team

- Details of research activity that falls outside the UK and links to local institutions

- Expected outcomes, impacts and benefits of research

- Dissemination (and feedback to participants where appropriate) and possible ethics implications of dissemination plans

- Measures taken to ensure confidentiality, privacy and data protection during and beyond the end of the project

- Members of Advisory Groups and whether they pose any risk to the safety of the researchers or participants.'

(2010: 1.8.1, pp14-15)

4.4 But perhaps, present readers might interject, surely what is being proposed is, as the FRE document proclaims, a minimum set of requirements and not a detailed model for ethics evaluation and conduct (2010: opening para, p7), and anyway it allows for 'light touch review' (2010: 1.1.2, p7). Protestations about being 'minimum' aside, the FRE document provides considerable and consequential detail. And because of how notions of risk, sensitivity and what is 'novel' are construed in it, a considerable swathe of perfectly ordinary and non-contentious social research will require a full ethics review by an REC rather than a 'light touch' one. We now turn to consider the detail provided about the RECs, returning to topics supposedly 'involving more than minimal risk' (2010: 1.2.3, p8) in Section 5.

4.5 The FRE document considers the possibility that 'secondary' ethics committees dealing with applications might be discipline- or School-specific, with a 'primary' university or sub-university level committee considering strategy and monitoring performance (2010: 1.3.1.1, paras 1 and 2, p10). However, this is then rejected, because discipline experts or even those at School level are described as 'too closely aligned with the interests of researchers' (2010: 1.4.3, p12). What it specifies instead is an at least seven member high level committee, which should have at least one 'lay member' and 'At least one member ... knowledgeable in ethics' (2010: 1.5.2, p12; see also 1.5 'Composition of Research Ethics Committees, 1.6 'Remit and responsibilities of Research Ethics Committees', 1.7 'Procedures for reviewing and approving research proposals', (2010: pp12-14). It must also be independent both of researchers making applications and the university it is based within:

'The membership of a REC is fundamental to ensuring that it has the range of expertise and the breadth of experience necessary to provide competent and rigorous review of the research proposals submitted to it, and to do so from a position that is independent of both the researchers and the institution in which it is located.' (2010: 1.5.1, p12)

What is envisaged here is presumably that the RECs will act in an independent, in the sense of a nonprejudiced, way. However, given the wide remit of the RECS to develop independent processes and working methods, we have serious concerns about their in-built lack of accountability, with no recourse back to the ESRC nor to any properly independent body, only to 'the institution' (whatever that might mean), or to another REC with reciprocal arrangements for hearing appeals.

4.6 The hardly minimum specification of REC structure continues,

'RECs should be multidisciplinary and comprised of both men and women. They must include at least one lay member with no affiliation to the university or research institution in question. There must be members who have broad experience of and expertise in the areas of research regularly reviewed by the REC who have the confidence and esteem of the research community. At least one member must be knowledgeable in ethics. There must be a chairperson. RECs would also benefit from including individuals who reflect ethnic diversity, users of specialist health, education or social services, where these are the focus of research activities, individuals with experience of professional care or counselling, and individuals with specific methodological expertise (for example, statistics or qualitative methods) relevant to the research they review. Taking all of this into account, good practice would suggest that RECs would normally need at least seven members.' (2010: 1.5.2, p12)

The RECs are seen, through their committee constitution, to have some kind of free-floating 'expertise' providing competence to evaluate the specificities of particular located pieces of research. We reject this notion of ethics as a general 'expertise', for a committee cannot build up supposed competence without the contextual and disciplinary know-how that real expertise comes from.

4.7 Is the problem of general competence solved by an REC calling on external reports on the research proposals they are dealing with? Certainly the $F R E$ document envisages the RECs using external experts to review proposals:

'An REC may seek advice and assistance from experts outside the committee in considering a research proposal. When this happens, the chair should establish that the experts have no conflict of interest in relation to the proposal.' (2010: 1.5.3, p12)

We should remind readers at this point that such proposals will have already been refereed by ESRC assessors, and thus are being made subject to a two-stage review. This provision for RECs seeking external expertise increases the sense of the dilution of the assessor system, for if REC 'expertise' is gained from the reports of external experts, then this replicates the assessor's role. 
4.8 The 'bottom line' powers of the RECs with regard to funding and the wider governance of what is deemed ethical research are spelled out:

'Institutional RECs should review each research proposal submitted and may approve it as submitted, approve it subject to meeting specified conditions or reject it on ethics grounds. Where a proposal is rejected or changes are required, feedback should be given to the researcher. The decision made for each proposal, and the grounds on which it was made, should be recorded and provided to the researchers, and a copy kept on file with the proposal for a specified minimum period consistent with the institution's policy on information retention, but in any case extending beyond the lifetime of the project. As far as possible institutional support for committees should help them to support new forms of research. In making decisions in a rapidly changing research environment RECs should abide by the FRE principles initially but in the final analysis may also need to use independent experts as well as their own experience and judgement in coming to decisions.' (2010: 1.7.1, p13)

The RECs, then, can approve and also require changes to or even reject a proposal which will have already been peer refereed and agreed by the ESRC's relevant Board to be outstanding and fundable. In addition, while, as the last sentence here indicates, 'RECs should abide by the FRE principles initially', they are expected to develop their own custom and practice, and clearly on the cards is that different RECs in different institutions are likely to operate in different ways.

4.9 The remit of the RECs in considering what is the 'ethics probity' of a research proposal considered is considerable, and also confused:

'This will entail a consideration of the design and proposed conduct of the research. These should be considered in terms of the ethics issues raised (for example, whether the method of recruitment proposed puts undue pressure on individuals to participate) and the way they are addressed. The scholarly or scientific standards of the proposal should be evaluated by appropriate peer review, typically provided by the funding agency as part of the refereeing process. The scholarly or scientific standards/merits of the research are not the responsibility of the REC. Where the REC needs greater understanding of the scientific or scholarly merit of a proposal in order to make a judgement about ethics issues, it should seek the advice of an independent researcher with experience and expertise in the research methods and paradigm described in the proposal.' (2010: 1.9.2, p15)

This positions ethics in the design and proposed conduct of a piece of research, and the scholarly and scientific aspects of the research, as though these are binaries rather than indissolubly linked. The ESRC, of all organisations, really ought to recognise that scholarly and scientific standards and considerations of research design and proposed conduct cannot be separated. Saying that what is proposed will not impact on the scholarly judgements of the ESRC's assessors is a nonsense for as long as the RECs are to review research design and the proposed conduct of research.

4.10 If a research proposal is refused ethics permission by an REC, then:

' $\ldots$ it is appropriate for the REC to give feedback on what needs to be done in order to meet the necessary ethical standards and achieve ethics approval.' $(2010: 1.4 .4$, p12)

This begs questions as to what is the point and status of the expert assessors who read and assess proposals for the funding councils. And the further question arises, under such a system why would someone agree to act as an ESRC assessor of research proposals, when the RECs can change or overturn the considered scholarly judgements of assessors reporting on a particular proposal?

4.11 This question becomes even more pertinent once the conditions of the RECs with regard to administrative resourcing, and workload and administration relief, are taken cognizance of:

'Universities and/or research organisations should provide the REC or RECs for which they are responsible with the necessary resources to carry out their responsibilities efficiently, effectively and independently. This includes, at a minimum, appropriate training for the members in the ethics, legal and scientific dimensions of the research that their REC reviews; adequate administrative and clerical support, and adequate resources, including recognition in workload planning and the allocation of academic responsibilities, to carry out reviews with due care and attention; and to attend meetings of the REC.' (2010: 1.10.1, p16)

ESRC assessors might well look longingly at being given administrative support and workload relief for the considerable amount of work that many do in the course of an academic year.

4.12 But is it all over, bar doing the research, once ethical clearance has been given by an REC and the funding already contingently agreed by the ESRC is finally obtained? The short answer is, no, the remit of the REC continues in three important respects, concerning on-going review, publication, and suspicions of non-compliance.

4.13 The on-going review of research even after passing the REC review is a constituent part of the process established in the FRE document:

'It is accepted that in some cases as research progresses, further ethics issues may arise. In these cases, Principal Investigators should go back to their RECs, check through the implications of the new developments and have any changes approved both by the REC and ESRC... In the End of Award Report to the ESRC, the Principal Investigator will be required to comment on any changes that have taken place, the ethics implications of these and how they were resolved. If ethics review is required at a later stage in the project, this should be discussed and funding arrangements agreed in advance with the ESRC.' $(2010: 1.9 .5, \mathrm{p} 16)$ 
statement. However, the last sentence here raises the possibility of 'ethics review... at a later stage in the project', with what this means fleshed out later in the document (see 4.15 below).

4.14 Publications too come into the remit of the RECs and their consideration of the adequacy of how proposals deal with ethical issues:

'Ethics issues may also arise in disseminating findings. In submitting the original proposal to the ESRC, potential risk to researchers, participants and others as a result of dissemination must be highlighted. These potential risks should also be considered in the application to the REC. In the End of Award Report to the ESRC, Principal Investigators will need to report any concerns and how they were overcome.' (2010: 1.9.6, p16)

Of course such issues can arise, but to date it has been within the scholarly competence of researchers, editors and publishers to consider such matters in context. That is, by considering it in the context of the particular research, with regard to the particular location/s it was carried out in, and regarding the publishing outlet selected. This provision is a yet further expansion of the remit of the RECs, and coupled with the third aspect of continuing ethics review is a very troubling one.

4.15 This third aspect concerns situations where a REC 'considers' there is researcher non-compliance with the approval given:

'Where an REC or designated sub-committee considers that a study is being conducted in a way which is not in accord with the conditions of its approval or in a way which does not protect the rights, dignity and welfare of research participants, it should initially bring together a meeting of all those concerned with a view to resolving the difficulties. In an extreme situation, the REC may withdraw its approval, and require that the research be suspended or discontinued. The ESRC must be informed of this decision and reserves the right to recoup its grant funding, pending further investigation, in extreme cases of ethics misconduct.' (2010: 1.11.5, pp16-17)

While we do not support ethics misconduct, we do want to raise the question of precisely how an REC might 'consider' such a thing to have happened. A snitch system appears on the research horizon, including where dissenting REC members might take it upon themselves to give continued scrutiny to particular research projects they do not approve of. But whatever, it is clear that a full on-going start to finish review is mandated in the FRE document.

\section{The heavy hand of 'light touch review'}

5.1 What does the 'light touch review' envisaged in the FRE document consist of and what are the issues and problems arising? In the first instance, the researcher using appropriate documentation decides whether a light touch or a full REC review (with both requiring submission to a REC) is required (2010: 1.1.2, p7), with 'All ESRC-funded awards... approved by at least a light touch ethics review' (2010: 1.1.3, p7). So just what is a 'light touch' review?

'Light touch reviews identify those projects where the potential for risk of harm to participants and others affected by the proposed research is minimal. In many cases this is the only ethics review necessary, and this can be undertaken using a pre-defined checklist (see Appendix A).' (2010: 1.1.1, p8)

5.2 What the FRE document specifies as research 'which would normally be considered as involving more than minimal risk' (2010: 1.2.3, p8) involves an array of perfectly ordinary and non-contentious research, which is now brought within the realm of a full REC review. Thus 'more than minimal risk' is identified as existing in relation to the following:

- Research involving potentially vulnerable groups

- Research involving those who 'lack capacity'

- Research involving sensitive topics

- Research involving deceased persons, body parts or other human elements

- Research involving groups where permission of a gatekeeper is normally required

- Research involving deception or without full and informed consent

- Research involving records of personal or sensitive confidential formation

- Research which might involve psychological stress

- Research where the safety of the researcher may be in question

- Research involving members of the public in a research capacity

- Research undertaken outside the UK

- Research involving respondents through the internet

- Other research involving visual/vocal methods

- Research which may involve sharing confidential information beyond the initial consent given'

(2010: 1.2.3, p8-10)

5.3 Conceived minimally and by reference to existing legalities, we have no problem with some of these headings. However, the way they are unpacked in the FRE document produces many potential difficulties. For instance, these categories presume research on 'participants' who may or may not be vulnerable or lack capacity, may or may not have given their informed consent. However, what may be involved, for instance regarding research outside the UK, and the use of visual and vocal methods, may well not involve participants at all. And while 'sensitive' has a serviceable and known definition within the UK's Data Protection Act 1998, how the term is used in the FRE significantly departs from and extends this.

5.4 The listings we find particularly confused or otherwise problematic are as follows.

Research involving sensitive topics: The full descriptor here is, '- for example participants' sexual behaviour, their illegal or political behaviour, their experience of violence, their abuse or exploitation, their 
mental health, or their gender or ethnic status. Elite Interviews may fall into this category.' (1.2.3, pp8-9). In part, this derives from 1998 UK Data Protection Act provisions, but other things have been inappropriately imported in. Thus, ethnicity in the Act concerns inquiries about ethnic origins, not a blanket embargo on research concerning ethnic status as one among a number of analytical categories. Also the Act is concerned with people's sexual lives and not with inhibiting gender as a research dimension. Even more oddly, 'elite interviews' are picked out in the FRE as likely to be sensitive and requiring a full ethics review, although there is - rightly - no mention of this in the Data Protection Act. Its inclusion here is a completely unacceptable and unjustifiable move towards protecting the more powerful.

Research involving deceased persons, body parts or other human elements: This listing, which has no more detail attached to it than the heading, is presumably directed towards interdisciplinary research where tissues and other bodily parts may be taken from 'deceased persons', as in The Section 2 'Frequently Asked Questions' section on 'Medical Research' (2010: p31). However, we raise it here because the heading is potentially confusing, as it is the only place where research on 'the dead' is recognised as falling within the ESRC's remit. However, rather than body parts, we are thinking here of research in social and economic history, historical sociology and historical anthropology. Many of the other categories presumed to be ethically 'risky' and requiring full review look very different once it is recognised that, for example regarding the historical census in the UK, the participants here whose records have been deanonymised without their full informed consent will come under the UK's 100 year legal rule for the release of such data because involving 'deceased persons'.

Research involving groups where permission of a gatekeeper is normally required: The full descriptor here is:
'Research involving groups where permission of a gatekeeper is normally required for initial access to members. This includes research involving gatekeepers such as adult professionals (eg. those working with children or the elderly), or research in communities (in the UK or overseas) where access to research participants is not possible without the permission of another adult, such as another family member (eg the parent or husband of the participant) or a community leader.' (2010: 1.2.3, p9).

It is entirely unclear what ethical point is being made about gatekeepers, opening up the spectre of RECs differentially interpreting the issues. In some research circumstances, gatekeepers may be helpfully used or even positioned as key informants (Doc and Biggy Muldoon come to sociological mind). In others, they may problematically stand between a researcher and a research population quite capable of giving informed consent - teachers and parents in some circumstances in relation to under 18s, for instance. The point we come back to is, 'it all depends' - and it takes a knowledgeable expert assessor to evaluate the appropriateness of the stance adopted.

Research undertaken outside the UK: The fuller version of the descriptor is '... where there may be issues of local practice and political sensitivities. In some cases partnership with a research organisation in the area involved may prove helpful. It is also necessary to check the requirements for ethics review in the countries included in the research' (2010: 1.2.3, p9). We are at a loss about why such research should in an a priori way be considered as involving more than minimal ethical risk. All social research involves issues of local practice and if not political and then other kinds of sensitivities, but this is a matter of life as we know it and not 'greater risk'. What is being suggested is that researchers should not only deal directly with participants with regard to consent and related matters, but also subject themselves to local structures in a quite different cultural, political and scholarly context. Not all research is in cuddly places, and this could mean being subject to totalitarian, authoritarian, racist, misogynistic practices, all legislated away under the bland terms 'partnership' and 'local practice'.

Research involving respondents through the internet: Although 'in particular where visual images are used, and sensitive issues discussed' is added to this heading, what comes across is that the internet is treated as though an undifferentiated 'it' and a kind of evil empire (2010: 1.3.2.5, p11). The ESRC's webpage from which the FRE document is downloaded comments that

'The issues surrounding internet and technology were the most frequently cited in the course of the consultation. In light of this, the revised framework seeks to address these concerns by recommending full ethics review where internet research or data sharing feature in a research proposal and may be judged necessary.' (2010: 'Internet and technology' p46)

What appears in the FRE document about internet research is superficial and lags behind custom and good practice in this research area and would be laughable if not tied to the ESRC's funding regime.

5.5 We now move on to pull together the detailed comments we have made on the ESRC's 2010 Framework for Research Ethics by considering the wider issues arising.

\section{Consultation, informed consent, ethics creep, REC governance, professional associations and peer assessment}

6.1 Our view is that the ESRC's Framework for Research Ethics is not fit for purpose. Some readers might of course respond to our discussion of issues arising from the FRE framework that none of what we discuss is intended, that the intention is simply to provide safeguards and the new provisions will not have the consequences we are concerned about because of good intentions all round. Intentions and eventualities are not the same thing, however, and the words on paper certainly bear the interpretation we have given them. In addition, the probability has to be recognised of RECs finding appropriate work to do to justify their resourcing, the training received, the workload and administrative relief given, and over time acting around their own rules of thumb and custom and practice, including by making use of external expert advisors, and with significant differences in the practices of different RECs coming into existence. Indeed, there is ample evidence of RECs (or Institutional Research Boards in the US) in other areas than the social sciences, and in other countries than the UK, doing precisely this, resulting in research design being shifted and moulded in sometimes major ways (Coomber 2002, Haggerty 2004, American Ethnologist 2006, Dingwall 2006, Reed 2007, Hedgecoe 2008, Hunter 2008). We do not accept 'good intentions', then, 
6.2 The first wider issue we want to consider concerns consultation and informed consent. We have serious concerns about the nature of consultation - or rather the dearth and brevity of consultation involved in producing the 2010 FRE document and the significant changes it includes. The FRE document makes much of fully informed consent and people knowingly 'signing up' for participation. We observe little of this happening with regard to the 2010 FRE framework itself. The wide consultation process that led to the ESRC's 2005 Framework for Research Ethics occurred over a three year period (Webster 2006). The FRE document comments that its consultation process was wide, while the only specific information it includes on this is that other UK funding bodies have signed up to the framework. However, the consultation process actually gave the professional associations which were consulted a three week period in which to respond, asking them to do so around three specific questions - 'Have there been any key developments in the last three years within the social sciences, or research more generally, that need to be explicitly addressed within the Research Ethics Framework?', 'In your experience, is all social science research being reviewed on a consistent basis or is ESRC funded or submitted research treated differently?' and 'Are you broadly content that the delegated authorities and management procedures associated with research ethics within ROs/Universities are clear and the delegation and decision making is properly, diligently and equitably exercised?' (ESRC Consultation Document 2009). No indication was given that this was part of producing a significantly changed FRE system; indeed the tenor of the first question here suggests modifications rather than major shifts. The result is that the contents of the FRE document have appeared as a fait accompli, the significance of the changes from the 2005 document have been unremarked upon, and the social science research community has not been consulted in an appropriate and sufficient way. By the ESRC's own FRE standards, the limited consultation process it engaged in should be considered unethical.

6.3 From our perspective, that of the ordinary social science researcher, there has not yet been a proper debate about the 2010 FRE framework. It is in this spirit we have written this response, as one among a number of contributions to a Debate Section on the ESRC's Framework for Research Ethics. A considerable body of research knowledge exists regarding the establishment and operations of RECs in other aspects of UK and wider research life, which can and should be brought to bear on the ESRC's document and its provisions for 'ethics governance'. There needs to be a detailed informed collective response which, even if it fails to make a dent on the ESRC, can help individual researchers find ways of dealing with the potentially extremely intrusive and controlling framework which has been instituted, around collective thinking about appropriate ways to manage this. ${ }^{[4]}$

6.4 The second wider issue to be signalled here concerns ethics governance as part of a wider 'audit creep'. Elsewhere, where Research Ethics Committees or their counterparts have been introduced, the remit of such committees has been extended and formalised over time, including by requiring unfunded research to conform to the same ethics review and clearance process (Bradburd 2006; Lederman 2006a, 2006b). This ethics creep (Haggerty 2004) operates using generalist ideas about ethics compliance rather than being more attuned to disciplinary ways of working and the specifics of particular research contexts (Webster 2006). The time-consuming (for the researcher) bureaucratisation of entirely routine social science research by drawing it into 'high risk' categories (Reed 2007, Hunter 2008) is not the only thing on the cards, for, as we noted earlier, elsewhere ethics creep has eventually extended to unfunded as well as funded research.

6.5 The third wider issue to be flagged concerns the likely impact of REC governance on research design and practice. Experience elsewhere indicates that ethics governance by RECs or their counterparts significantly skews what is researched and how it is researched in order to 'play the ethics game' with regard to procedures found unnecessarily intrusive and bureaucratic (Dingwall 2007, Richardson \& McMullan 2007). In the longer term, researchers are likely to play safe, by shaping project focus, design and conduct so as to best-guess the particularities of local RECs (Hedgecoe 2008). Many years of the Research Assessment Exercise (now REF) process have gone into reconfiguring UK social science as research-led and of an internationally very high standard (HAPS 2010); audit creep extended to ethics governance by local RECs will eventually unpick this by reducing 'blue skies' to 'what my REC wants'.

6.6 The fourth wider issue to be raised concerns the relationship of RECs and the research community around the unethical nature of abstracted ethics judgements and ethics regulation (Dingwall 2006, 2007; Hammersley 2006, 2009). There is not one social science community, with very different approaches existing which impact on all aspects of research, differentiating the social sciences from each other, differentiating even different paradigms and methodologies from others in the same discipline. These particularities matter because they relate to fundamental matters of how epistemology and ontology are conceived, while the supposed universal competence of RECs tends to ignore such particularities to focus on 'generalities' which are not in fact general at all. As Hammersley (2009) comments, RECs end up acting unethically because operating their own internalist notions of good practice, but which may depart signally from professional, disciplinary or paradigmatic notions of good ethics.

6.7 The fifth wider issue we want to table concerns professional guidelines and their relationship to the FRE framework and the role of the RECs. The FRE does say early on in the document that researchers should use their professional disciplinary standards to decide the kind of ethical issues that exist and whether a 'light touch' or full review is called for (2010: 1.1.2, p7). However, the process that is then detailed completely sidelines the role of professional associations and the codes developed to guide the research and other practices of their members. The professional bodies of sociologists, anthropologists, social policy specialists and so on have no recognised place within the FRE framework, and yet they are the fundamental focal point for ensuring good practice across many aspects of professional conduct, including research activities and publications from these (ASA 1999, BPS 2009, BSA 2002/4, PSA nd, SRA 2003). It is instructive here to compare the approaches of the Association of Internet Researchers and the ESRC 2010 FRE document, with the AolR ethics guidelines emphasising that 'Researchers and those charged with research oversight are encouraged in the first instance to turn to the discipline-specific principles and practices of research.' (AolR 2002, p2; see also Johnson 2009). A FRE ethics framework for the social sciences that does not start from the ethical guidelines of the professional disciplinary associations concerned is deficient and, while it may have financial clout, it lacks moral and intellectual credibility. 
6.8 The sixth and final wider issue to be commented on concerns the ESRC's system of expert assessors evaluating research proposals for funding. We will not repeat the arguments made earlier about this, although we do want to insist that there are major implications for the continuing viability of the assessor system if there is to be a second stage assessment as part of a dual system in which the RECs control funding decisions and can commission their own expert assessors. Instead, we suggest that a better solution to the felt-need from the ESRC for greater ethical governance is to provide appropriate training and workload relief for those active researchers who act as assessors of research proposals for the ESRC. The assessors could then give this work appropriate time (rather than fitting such requests on top of their normal workload), including the extended ethical accounting now required as part of applying for funding to the ESRC, also introducing more efficiency into the assessor system. There is already a useful response mode to assessors' reports, while workload relief would ensure both a greater willingness to serve and more rapidity in providing reports.

6.9 What now? Rather than crying in the dark, our purpose in writing this assessment of the ESRC's Framework for Research Ethics and the wider issues it raises is to encourage debate on these matters, and to do so expeditiously. In doing this within the electronic pages of a Sociological Research Online debates section, we hope to engage in particular the sociological contingent of the social sciences in the UK in thinking about the ESRC's framework and what it entails. We plan for four things, along with this: one, to publish a wide range of responses, both to our commentary and also on the Framework for Research Ethics itself; two, to invite a response to all these from the ESRC; three, to encourage the British Sociological Association to make representations to the ESRC about the urgent need for more appropriate consultation processes in the future; and four, to promote a further round of debate at the next BSA Annual Conference.

\section{Notes}

${ }^{1}$ Of course we are aware of the need to protect 'human subjects' (Kent et al 2002); but must also emphasise that routine social science research does not require the same degree of bureaucratic ethical regulation as medical research (see also Dingwall 2006, Hammersley 2009).

2 We recognise that the terms 'audit creep' and 'mission creep' (and also 'ethics creep') are widely used. Lederman's particular usage is pertinent for our following argument; see also the introduction to the November 2006 special issue of the American Ethnologist edited by her on bureaucratic ethics regulation (Lederman 2006a).

${ }^{3}$ All following references to the ESRC's FRE document provide year and section and page numbers only.

${ }^{4}$ Reed (2007) comments about how researchers might 'manage' aspects of this, and Wiles et al (2007; see also Crow et al 2006) suggest that researchers position themselves and their work somewhere between the more optimistic and more pessimistic views of ethics in relation to informed consent. While such discussions are helpful, we are more interested in collective ways of responding and protesting, as spelled out in section 6 of this paper.

\section{References}

ASSOCIATION OF INTERNET RESEARCHERS (2002) Ethical Decision-Making and Internet Research: Recommendations from the AolR Working Committee, <http://www.aoir.org/reports/ethics.pdf>

ASSOCIATION OF SOCIAL ANTHROPOLOGISTS (1999) Ethical Guidelines for Good Research Practice Brighton: ASA <http://www.theasa.org/ethics/guidelines.htm>

BRADBURD, Daniel (2006) 'Fuzzy boundaries and hard rules: unfunded research and the IRB' American Ethnologist 33: 492-8.

BRITISH SOCIOLOGICAL ASSOCIATION (2002/4) Statement of Ethical Practice Durham: BSA $<$ http://www.britsoc.co.uk/equality/Statement+Ethical+Practice.htm>

British Psychological Society (2009) Code of Ethics and Conduct Leicester: BPS <http://www.bps.org.uk/the-society/code-of-conduct/code-of-conduct_home.cfm>

COOMBER, Ross (2002) 'Signing your life away: Why research ethics committees shouldn't always require written confirmation that participants in research have been informed of the aims of a study and their rights - the case of criminal populations' Sociological Research Online, 7, 1, <http://www.socresonline.org.uk/7/1/coomber.html>

CROW, Graham, Rose Wiles, Sue Heath \& Vikki Charles (2006) 'Research ethics and data quality: the implications of informed consent' International Journal of Social Research Methodology 9: 83-95.

DINGWALL, Robert (2006) 'An exercise in fatuity: research governance and the emasculation of HSR' Journal of Health Services Research Policy, 11, 4, 193-4

DINGWALL, Robert (2007) 'Turn off the oxygen...' Law and Society Review 41, 4, 787-95

ESRC (2005) Research Ethics Framework Swindon: ESRC <http://www.esrcsocietytoday.ac.uk/ESRCInfoCentre/Images/ESRC_Re_Ethics_Frame_tcm6-11291.pdf>

ESRC (2009) ESRC Consultation Document - Review of the ESRC Research Ethics Framework Swindon: ESRC. 
<http://www.esrcsocietytoday.ac.uk/ESRCInfoCentre/Images/Framework\%20for\%20Research\%20Ethics\%202010_tcm635811.pdf> (accessed August 2010)

HAGGERTY, Kevin (2004) 'Ethics creep: governing social science research in the name of ethics' Qualitative Sociology 27, 4, 391-414.

HAMMERSLEY, Martyn (2006) 'Are ethics committees ethical?' Qualitative Researcher 2: 4-10.

HAMMERSLEY, Martyn (2009) 'Against the ethicists: on the evils of ethical regulation', International Journal of Social Research Methodology, 12, 3, 211-225.

HAPS (2010) Report of the International Benchmarking Review of Sociology Swindon: ESRC <http://www.esrcsocietytoday.ac.uk/ESRCInfoCentre/Support/Evaluation/ibr/IBR_Sociology.aspx> (accessed August 2010)

HEDGECOE, Adam (2008) 'Research ethics review and the sociological research relationship, Sociology, $42,5,873-886$.

HUNTER, DLH (2008) 'The ESRC research ethics framework and research ethics review at UK universities: rebuilding the Tower of Babel REC by REC', Journal of Medical Ethics, 34, 815-20.

JOHNSON, Deborah G. (2009) Computer Ethics: Analyzing Computer Technology New Jersey: Pearson Education Inc.

KENT, Julia, Emma Williamson, Trudi Goodenough, \& Richard Ashcroft (2002) 'Social science gets the ethics treatment: research governance and ethical review' Sociological Research Online, 7, 4, <http://www.socresonline.org.uk/7/4/williamson.html>

LEDERMAN, Rena (2006a) 'Introduction: Anxious borders between work and life in a time of bureaucratic ethics regulation' American Ethnologist 33: 477-81.

LEDERMAN, Rena (2006b) 'The ethics of working at home: IRB "mission creep" as context and content for an ethnography of disciplinary knowledges' American Ethnologist 33: 482-91.

POLITICAL STUDIES ASSOCIATION (nd) Guide to Good Professional Conduct Newcastle-upon-Tyne, PSA <http://www.psa.ac.uk/Content.aspx?ParentID=3>

REED, Kate (2007) 'Bureaucracy and beyond: The impact of ethics and governance procedures on health research in the social sciences' Sociological Research Online 15, 5 <http://www.socresonline.org.uk/12/5/18.html>

RICHARDSON, Sue \& Miriam McMullan (2007) 'Research ethics in the UK: What can Sociology learn from Health?' Sociology 41, 6: 1115-32.

SOCIAL RESEARCH ASSOCIATION (2003) Ethical Guidelines London: SRA <http://www.thesra.org.uk/documents/pdfs/ethics03.pdf>

WEBSTER, Andrew (2006) 'Social science ethics: the changing context for research' Clinical Ethics 1: 3940.

WILES, Rose, Graham Crow, Vikki Charles \& Sue Heath (2007) 'Informed consent and the research process: following rules or striking balances', Sociological Research Online, 12, 2, <http://www.socresonline.org.uk/12/2/wiles.html> 